\title{
A Importância de um Sistema Nacional de Inovação para o Setor de Termoplásticos no Mercosul
}

\author{
Maria J. S. Ferreira Netto e Adelaide M. S. Antunes \\ Sistema de Informações Sobre a Indústria Química - SIQUIM, Escola de Química, UFRJ, Brasil \\ Otilia Vainstok \\ Centro de Estudios Avanzados - UBA, Argentina
}

Resumo: O presente trabalho discute a interação entre os numerosos atores e instituições que participam do processo de inovação em todas as etapas da cadeia produtiva dos termoplásticos. A importância da interação destes para conseguir um desempenho que produza benefícios privados e sociais são apresentados através da proposta de desenvolvimento e criação de um sistema nacional de inovação (SNI) para o segmento de termoplásticos no Brasil e na Argentina. Através de uma nova visão institucional e política ampliam-se as redes de intercâmbio e as parcerias com as principais instituições e organismos públicos de fomento à ciência e tecnologia ao mesmo tempo em que o setor privado é incentivado para um maior intercâmbio e cooperação

Palavras-chave: Termoplásticos, sistema nacional de inovação, inovações tecnológicas, ciência e tecnologia.

\section{The Importance of a National System of Innovation for the Thermoplastics Sector in the Mercosul}

\begin{abstract}
The present approach discusses the interaction among numerous actors and institutions that participate in the innovation process in every productive chain of thermoplastics. The importance of their interaction to get a result that produces private and social benefits are presented through the proposal of criation and development of National System of Innovation (NIS) for the segment of the thermoplastics in Brazil and Argentina. The interchange nets and the partnerships with the main institutional public organisms of foment for science and technology are amplified through a new institutional and political vision. At the same time the private sector is stimulated to make a better exchange and cooperation.
\end{abstract}

Keywords: Thermoplastics, national system of innovation, technological innovations, science and technology.

\section{Introdução}

O setor de termoplásticos, pertencente à segunda geração petroquímica, constitui o principal sub-setor desta indústria que dentro do complexo químico interage com os mais diversos tipos de indústrias igualmente importantes e estratégicas. A ampla e diversificada possibilidade de utilização dos termoplásticos foi sendo alcançada pouco a pouco ao substituir os produtos tradicionais, com mercados tradicionais e já estabelecidos, mas também na elaboração destes a um menor custo, o que ocasionou o fortalecimento da capacidade técnico-científica e da infra-estrutura de P\&D através do desenvolvimento e difusão das inovações e a busca de novas tecnologias. Esta conjuntura exige que haja um intenso intercâmbio entre os numerosos atores e instituições que participam do processo de inovação. A importância da interação destes para conseguir um desempenho que pro-

Autor para correspondência: Maria J. S. Ferreira Netto, Sistema de Informações Sobre a Indústria Química - SIQUIM, Escola de Química, UFRJ, Bloco E, CEP: 21949-900, Rio de Janeiro, R.J. E-mail: zeze@eq.ufr.br 
duza frutos em termos de benefícios privados e sociais são apresentados através de um sistema nacional de inovação (SNI). O SNI compreende todos os elementos que contribuem para o desenvolvimento, introdução, difusão e utilização das inovações, incluindo além das universidades, centros de pesquisa e laboratórios de $\mathrm{P} \& \mathrm{D}$ e outros agentes dos setores público e privado aparentemente distantes da ciência e tecnologia.

Nos países industrializados, mas ainda em desenvolvimento, nos quais há estabilidade de preços e que apresentam um franco crescimento econômico, o aumento substancial das importações de bens de capital e os fluxos de investimento estrangeiro direto (IED), o crescimento da produtividade do trabalho, o processo de modernização tecnológica são ferramentas necessárias ao êxito das políticas públicas.

A abertura da economia às importações é um fator de estímulo à melhoria da eficiência do setor produtivo, pois ocasiona uma maior competição no mercado local devido à presença destas, facilitando também o acesso a máquinas e equipamentos de última geração.

A liberalização do IED promove a incorporação e difusão dos conhecimentos técnicos e gerenciais dos investidores estrangeiros. Por outro lado, a desregulamentação dos acordos de transferência de tecnologia estimula o processo de modernização tecnológica.

A estabilidade macroeconômica, as vantagens decorrentes da abertura dos mercados e o melhor funcionamento dos mesmos e das organizações públicas mostram que cada vez mais além do crescimento econômico, a eqüidade, a coesão social, o meio ambiente e o desenvolvimento democrático são importantes para o desenvolvimento das nações o que originou uma nova e importante visão dos problemas da modernização tecnológica e como impulsioná-los ${ }^{[1]}$.

Devido à complexidade da aquisição, adaptação e desenvolvimento de novas tecnologias, da transmissão da informação e dos conhecimentos serem imperfeitas e as empresas atuarem de maneira reservada, as políticas públicas terão um papel importante especialmente com respeito ao setor de termoplásticos no Brasil e na Argentina, pois este segmento industrial tem ainda algumas dificuldades em adaptar-se às novas regras decorrentes da globalização dos mercados.
Ainda que a importação de máquinas e equipamentos e a entrada do IED facilitem a modernização tecnológica e os aspectos codificáveis do conhecimento tecnológico propiciem transações comerciais, o processo em questão gera uma série de externalidades positivas e sinergias que não são simplesmente refletidas pelo mercado e que irão requerer coordenação e promoção por parte de instâncias governamentais, o que significará abandonar o "laissez faire".

Uma nova visão institucional e política para o segmento em questão seriam sem dúvida um fato auspicioso, pois ampliaria as redes de intercâmbio e as parcerias com as principais instituições e organismos públicos de fomento à ciência e tecnologia $(\mathrm{C} \& \mathrm{~T})$ ao mesmo tempo em que incentivaria o setor privado para um maior intercâmbio e cooperação por meio da implementação de um sistema nacional de inovação (SNI) para o segmento de termoplásticos no Brasil e na Argentina.

\section{Tecnologia, inovação e sistema nacional de inovação}

A tecnologia intangível traduz-se num código de conhecimentos gerados pelos departamentos de P\&D de firmas especializadas. Esses departamentos utilizam em maior ou em menor quantidade os conhecimentos científicos que são gerados nas universidades e centros de pesquisa e desenvolvimento.

$\mathrm{Na}$ lógica do enfoque linear da política científica e tecnológica ${ }^{[2]}$, os resultados dos esforços de P\&D no setor público se extendem até os usuários como bens públicos. Nas empresas privadas os esforços inovadores gerados nos departamentos de P\&D se difundem para a produção e comercialização chegando ao mercado sob forma de inovações de produtos e processo.

À medida que os conhecimentos estejam codificados, seus usuários podem facilmente reproduzi-los sem maiores dificuldades. Em conseqüência, a tecnologia constituiria um fator exógeno para a maior parte das empresas. Quando está sob domínio privado, através de patentes ou outros mecanismos, sua aquisição deve ocorrer por meio de licenciamentos ou joint-ventures. Se está disponível, pode ser obtida simplesmente como informação técnica.

Nos enfoques não ortodoxos, os principais objetivos da política científica e tecnológica assegurariam 
um fluxo contínuo de inovações - mediante financiamentos governamentais à pesquisa científica e tecnológica que universidades e centros de pesquisa desenvolvem, a proteção à propriedade intelectual e os incentivos fiscais aos gastos efetuados em P\&D realizados pelo setor privado - e favoreceriam a difusão das inovações no tecido produtivo mediante um eficiente sistema de informações.

Nas teorias evolucionistas ou neoschumpeterianas, os conhecimentos científicos e tecnológicos não são perfeitamente codificáveis e, portanto sua transferência é imperfeita. Tanto para gerar conhecimento como para utilizá-los, é necessário um esforço endógeno baseado na acumulação de capacitações científicas, técnicas e organizacionais, o que por sua vez propicia aumentos da produtividade e da eficiência acarretando um fluxo crescente de inovações em matéria de produtos e processos de produção.

Numa economia globalizada, na qual o IED cresce mais rapidamente que o comércio internacional e onde os custos de transmissão da informação e de transporte reduzem-se cada vez mais, os fluxos externos de conhecimentos tecnológicos são extremamente relevantes. Como os conhecimentos gerados nos processos são tácitos, cumulativos e localizados existiria um espaço importante em nível nacional e regional para o desenvolvimento de capacidades tecnológicas endógenas, as quais são imprescindíveis para a absorção de maneira eficiente de tudo que seja proveniente do exterior e obviamente na adaptação, modificação e geração de novos conhecimentos.

Apesar da crescente interdependência no que se refere a fluxos de investimento e de tecnologia, os primeiros estudos sobre SNI realizados em vários países da Organização para a Cooperação e o Desenvolvimento Econômico (OCDE) destacam que as empresas baseiam seu processo inovador fundamentalmente nos seus próprios esforços de $\mathrm{P} \& \mathrm{D}$ e recorrem relativamente pouco a fluxos importados $^{[3]}$.

A maior parte dos países em desenvolvimento apresenta em geral a situação oposta. Além de serem poucos os recursos destinados à $\mathrm{P} \& \mathrm{D}$ no setor privado, também há uma grande interação das firmas com os fornecedores tecnológicos do exterior, mais do que com firmas ou instituições locais, onde as vinculações são em geral unidirecionais (licenciamentos, franquias, subcontratação) e são escassos os acordos bidirecionais com relação a $\mathrm{P} \& \mathrm{D}$, a produção ou a comercializaçãa ${ }^{[4]}$. Com relação ao segmento de termoplásticos no Mercosul, o desenvolvimento de acordos de cooperação técnica; o intercâmbio de informações entre centros de pesquisa, universidades, empresas, transformadores e usuários finais; a pesquisa tecnológica conjunta entre universidades de ambos os países; a formação e capacitação de recursos humanos; a redução do impacto ambiental dos processos produtivos representará as potencialidades e o fortalecimento a médio e longo prazo de um SNI em termoplásticos.

Os numerosos atores e instituições que participam do processo de inovação e a importância da interação destes para um desempenho inovador que se traduza em benefícios privados e sociais foi bem definido na literatura neoschumpeteriana pelo conceito de SNI.

A primeira definição do SNI foi apresentada por Freeman $^{[5]}$ que o identificava como uma rede de instituições no setor público e privado cujas atividades e interações teriam como objetivo iniciar, importar, modificar e difundir novas tecnologias. Já Lundvall ${ }^{[6]}$, Nelson ${ }^{[7]}$ e Edquist ${ }^{[8]}$ analisam o SNI de diversas formas e baseiam-se em diferentes experiências nacionais.

Edquist $^{[8]}$ analisa muito bem o conceito de SNI, sua apreciação de que se trata não de uma teoria formal, mas também de um marco conceitual que aborda a problemática a partir de um enfoque holístico, interdisciplinar e histórico, embora conceitualmente difuso.

De maneira resumida, o enfoque principal do SNI considera a inovação e a aprendizagem como aspectos cruciais, se bem que as empresas sejam a espinha dorsal do SNI, estas não inovam sozinhas pois a inovação é um processo interativo e portanto o enfoque propõe a interação dos diferentes atores e instituições que participam no complexo processo coletivo. A diferença entre o modelo linear de inovação que enfatizava especialmente a geração de inovações e o SNI reside no fato em que neste último a difusão é mais importante que a geração de inovações.

Os enfoques baseados no SNI referem-se a maiores ou menores inovações de produtos e processos. Por outro lado, não só referem-se às inovações nos países que estão na fronteira tecnológica 
mas também dos que seguem a estratégia de alcançar as economias mais avançadas e manter-se no seu nível ${ }^{[9]}$.

Ao mesmo tempo, estes enfoques fogem à costumeira dicotomia que aborda o problema em função de somente duas instituições fundamentais - o mercado e o Estado - e também incluem outras tais como universidades, os bancos, a legislação da propriedade intelectual, os centros de pesquisa e de serviços tecnológicos.

Além das enormes dificuldades que se apresentam na identificação e quantificação dos diferentes indicadores - além dos gastos com P\&D e o número de patentes obtidas - os pontos mais fracos deste enfoque estão vinculados com a relevância dos insumos provenientes do exterior relacionados aos esforços endógenos de absorção e geração de inovações e principalmente aos aspectos normativos das políticas públicas dos SNI.

O processo de aquisição dos conhecimentos científicos, técnicos e organizacionais que permitirão a utilização de maneira eficiente das tecnologias disponíveis é prolongado, imprevisível e de alto risco. Implica no desenvolvimento de capacidades tecnológicas e de organização mediante esforços de aprendizagem no processo de produção (learning by doing), na comercialização e no contato com os clientes (learning by using) na busca incessante de novas soluções técnicas nas unidades de P\&D ou em instâncias não tão formais como nos escritórios técnicos (learning by searching ). Além de importantes esforços in house, este processo implica na interação com os fornecedores de equipamentos, partes e componentes; com os licenciadores; com os sócios estrangeiros; com institutos tecnológicos e universidades, com os setores produtivos, com os transformadores, com os usuários finais e os clientes (learning by interacting). Trata-se de um processo coletivo de aprendizagem cujo epicentro são as próprias empresas produtoras, no caso as empresas produtoras de termoplásticos e os diferentes setores onde atuam, tais como automobilístico, eletro-eletrônico, construção civil entre outros; estando também envolvidos outros atores e instituições públicas e privadas.

O caráter tácito, localizado e acumulativo do conhecimento tecnológico, a ênfase no processo de aprendizagem e nas diferentes fontes que o motivam, bem como a importância da retroalimentação e das nume- rosas interações que o caracterizam e o induzem, caracterizam um complexo e dinâmico quadro social que difere completamente do esquema simplificado com que este tema é abordado pela principal corrente econômica.

O conhecimento tecnológico é um requisito ao resultado do processo produtivo. Em nível individual e organizacional ocorre um processo de maturação à medida que se acumulam experiências, há a expansão das atividades atuais e outras são empreendidas. Esse processo de maturação gera diversas formas de capital humano individual e organizacional. Em ambos os casos, a aprendizagem está ligada com a educação dos recursos humanos envolvidos, de modo que é gerada uma complementariedade entre o capital humano tecnológico e o educativo. Esse capital não é totalmente apropriável pois os conhecimentos são ensinados ou transmitidos, os recursos capacitados podem deslocar-se entre as organizações e obviamente quando estão incorporados em equipamentos e insumos podem ser adquiridos. Isto origina externalidades de vários tipos que transformam tanto o capital tecnológico como o capital educativo em uma forma de capital social que podemos denominar "conhecimento capital". A acumulação desse capital é extremamente facilitada quando existem instituições apropriadas que apóiem seu desenvolvimento, que gerem interações dinâmicas entre o sistema educacional, os centros de pesquisa tecnológicos e as empresas permitindo a ampla utilização das economias de escala da pesquisa e as externalidades que caracterizam o conhecimento tecnológico. Estas instituições, os "sistemas nacionais de inovação" são elementos essenciais ao "conhecimento capital" ${ }^{1]}$.

A noção de capacidade tecnológica tenta capturar a grande variedade de conhecimentos e habilidades requeridos para comprar, assimilar, utilizar, adaptar, mudar e criar tecnologias. Este conceito está mais à frente das noções tradicionais de engenharia e knowhow, pois inclui o conhecimento tanto dos procedimentos e estruturas organizacionais como dos padrões de comportamento. As firmas necessitam de certos ativos complementares para criar, mobilizar e melhorar suas capacidades tecnológicas entre os quais se pode incluir produção/fabricação, distribuição, assistência técnica/serviços, marketing, reconhecimento de marca, softwares de apoio, entre outros ${ }^{[10]}$. 
Ciência e tecnologia: 0 que poderia ser realizado no mercosul?

Bem antes de Freeman ${ }^{[5]}$ definir um sistema nacional de inovação, o Brasil e a Argentina já haviam iniciado, no período de 1950-1980, as bases infra-estruturais e as capacidades básicas de seus SNI. Entretanto, a crise da década de 80 em ambos os países, a falta de recursos, assim como o predomínio das posturas liberais, provocaram: o envelhecimento excessivo da infraestrutura física e dos equipamentos para a realização de pesquisa básica e aplicada; o enfraquecimento das comunidades científicas, pela precariedade das condições de pesquisa e, os baixos salários dos pesquisadores que, de certa forma, obrigou-os a buscar universidades e instituições estrangeiras; além da diminuição do processo de inovação nas empresas.

Já na década de 90 esse quadro sofre modificações pois se inicia pouco a pouco a especialização tecnológica nacional, e os vários atores envolvidos contribuem para um projeto de construção pela sociedade da "capacidade tecnológica nacional", onde uma cultura inovadora abarca todos os setores e onde a P\&D é vista como imprescindível e seus objetivos passam a ser compartilhados e demandados pela sociedade. Segundo Cassiolato e Lastres ${ }^{[11]} \mathrm{em}$ um ambiente crescente e intensamente dinâmico como na atualidade, os níveis de competitividade são rapidamente alcançados e a capacidade de ingresso e permanência em novos mercados é dificultada. O fortalecimento da capacidade técnico-científica e da infra-estrutura de P\&D é uma condição primordial para o desenvolvimento.

O desenvolvimento da "capacidade tecnológica nacional" é necessário na determinação do tipo de transferência de tecnologia. Segundo Lall ${ }^{[12]}$, os aspectos pontuais e específicos que definirão qual o tipo de transferência ocorrerá, somente quando de sua negociação, podem ser:

- Transferência superficial que não permite a quem recebe a tecnologia operar com a informação recebida nem introduzir melhorias;

- Transferência profunda que permite a quem recebe a tecnologia incorporar mudanças e melhorias bem como há a capacitação de todos os recursos humanos envolvidos na sua operação.

Conforme Chudnovsky ${ }^{[13]}$, pode ser observado na Tabela 1 que os dispêndios em ciência e tecnologia do Brasil, após a implantação do Plano Real e da Argentina, após a segunda metade da década de 90, estão bem distantes do que ocorre nos países industrializados onde esse gasto supera $2 \%$ do PIB. O dispêndio em ciência e tecnologia no Brasil tem sido cerca de quatro vezes maior que o da Argentina em termos absolutos; correspondente ao dobro quando expresso em relação ao PIB. Em relação aos gastos em $P \& D$ estes foram de $0,76 \%$ do PIB para o Brasil e de $0,42 \%$ do PIB para a Argentina.

Conforme indicado na Tabela 2, pode-se observar que o número de pesquisadores envolvidos em ambos os países ainda é bem abaixo do observado que nos países industrializados e na Coréia do Sul. Entretanto há uma melhor situação relativa para a Argentina em relação à proporção pesquisador/população economicamente ativa (PEA), se comparado ao México, Brasil e Chile.

Segundo Brito Cruz ${ }^{[14]}$, no Brasil, $68 \%$ dos pesquisadores estão nas universidades, $21 \%$ nos institutos e centros de pesquisas públicos e $11 \%$ nas empresas privadas; na Argentina, 52\% dos pesquisadores estão nas universidades públicas e privadas bem como em entidades sem fins lucrativos, $36 \%$ nos institutos e centros de pesquisas públicos e $12 \%$ nas empresas privadas.

Com relação ao segmento de termoplásticos, em

Tabela 1. Investimentos em Ciência e Tecnologia

\begin{tabular}{ccc}
\hline \multirow{2}{*}{ País } & \multicolumn{2}{c}{$\begin{array}{c}\text { Investimento em ciência e } \\
\text { tecnologia }\end{array}$} \\
\cline { 2 - 3 } & US\$ bilhões & \% do PIB \\
\hline Estados Unidos & 184,30 & 2,48 \\
Jlemano & 76,00 & 2,78 \\
França & 37,15 & 2,48 \\
Coréia do Sul & 26,72 & 2,38 \\
Espanha & 12,20 & 2,69 \\
Brasil & 4,38 & 0,92 \\
México & 1,11 & 0,87 \\
Argentina & 1,35 & 0,33 \\
Chile & 0,40 & 0,46 \\
\hline
\end{tabular}

Fonte: Adaptação de Chudnovsky ${ }^{[13]}$ 
ambos os países, a totalidade dos pesquisadores está nas universidades, nos institutos e centros de pesquisas públicos e privados; sendo muito pequena a quantidade de pesquisadores nas empresas privadas.

Por outro lado o intercâmbio entre universidades com os setores de ciência e tecnologia e, sobretudo, com a indústria começa agora a articular-se. Até bem pouco tempo atrás este intercâmbio era bem limitado, comprometendo seriamente não somente a capacidade de gerar inovações bem como a capacidade de absorver novas tecnologias.

A elevação a longo prazo da capacidade científica com investimentos contínuos no sistema educativo, no desenvolvimento e melhorias das universidades (avaliação da docência superior, da pesquisa básica e aplicada desenvolvida por estas, o envio de profissionais e pesquisadores para aperfeiçoamento no exterior) já começam a reverter este quadro. Os trabalhos e a formação de parcerias que as universidades estão desenvolvendo já demonstram que os setores produtivos começam a buscar nas universidades e centros de pesquisa a solução de suas demandas. Entretanto esses investimen-

Tabela 2. Relações entre pesquisadores e PEA

\begin{tabular}{llc}
\hline \multicolumn{1}{c}{ País } & \multicolumn{2}{c}{ Pesquisadores } \\
\cline { 2 - 3 } & (número) & PEA \\
\hline Estados Unidos & 962700 & 7,4 \\
Japão & 140000 & 5,0 \\
Alemanha & 240802 & 5,7 \\
França & 129780 & 4,9 \\
Coréia do Sul & 98764 & 4,9 \\
Espanha & 41681 & 2,8 \\
Brasil & 37300 & 0,7 \\
México & 19434 & 0,6 \\
Argentina & 22147 & 1,9 \\
Chile & 6429 & 1,3 \\
\hline
\end{tabular}

Fonte: Adaptação de Chudnovsky ${ }^{[13]}$

Nota: $\mathrm{O}$ número de pesquisadores está compreendido entre os anos de 1994 e 1998. tos são ainda relativamente pequenos em relação às necessidades de ciência e tecnologia para a formação e desenvolvimento de um SNI.

Sob o enfoque do SNI, inicialmente os esforços em ciência, tecnologia e inovação devem ser orientados em função das demandas de bens e serviços econômicos e das necessidades sociais e regionais do país que irão compor as políticas setoriais e promoverão a articulação e vinculações entre os diversos atores e instituições dos setores público e privado participantes de processo de geração, difusão e absorção de conhecimentos e inovações

No Brasil, o Conselho Nacional de Desenvolvimento Científico e Tecnológico (CNPq) mantém diversos programas de incentivo ao desenvolvimento científico e tecnológico, que visam primordialmente, garantir a formação e o desenvolvimento de grupos de pesquisas nacionais, capacitados para gerar produção científica e acadêmica, com enfoque na ciência básica, de nível internacional bem como fortalecer a competitividade das empresas instaladas no País; o Programa de Apoio ao Desenvolvimento Científico e Tecnológico - (PADCT) é fruto de acordos de desenvolvimento e incentivo à geração endógena de conhecimento, celebrados entre o governo brasileiro e diversos organismos internacionais, permitindo a difusão e transferência de tecnologia do setor acadêmico para o setor industrial e a implementação de instrumentos adequados de interação entre esses dois setores, tanto em nível nacional como internacional, a FINEP, empresa pública vinculada ao Ministério da Ciência e Tecnologia (MCT), atuando na ampliação da competitividade das empresas brasileiras pela difusão e uso do conhecimento; dotando o país de base científica e tecnológica adequada às necessidades do setor produtivo e dos serviços públicos, identificando oportunidades de inovação a partir de novos conhecimentos científicos e tecnológicos, acelerando a incorporação de conhecimento pela sociedade entre outros objetivos. Há ainda instituições de fomento à pesquisa que têm por objetivo a promoção e o desenvolvimento científico e tecnológico em âmbito dos estados bem como o SEBRAE - Serviço Brasileiro de Apoio às Micro e Pequenas Empresas que é uma instituição técnica de apoio ao desenvolvimento da atividade empresarial de pequeno porte, voltada para o fomento e difusão de programas e projetos que visam à promoção e ao fortalecimento 
das micro e pequenas empresas. É predominantemente administrado pela iniciativa privada. Constitui-se em serviço social autônomo - uma sociedade civil sem fins lucrativos que, embora operando em sintonia com o setor público, não se vincula à estrutura pública federal. É uma entidade empresarial voltada para atender ao segmento privado, embora desempenhe função pública e tenha sempre em consideração as necessidades do desenvolvimento econômico e social do Brasil

$\mathrm{Na}$ Argentina, a presença governamental se concretizou após a criação em 1997 do Gabinete Cientifico Tecnológico del Gobierno (GACTEC) como um órgão de planejamento, fixação de metas, coordenação e captação de financiamentos através de um conjunto de programas que visam atender a assuntos específicos e políticas setoriais. No âmbito setorial e regional a complementação e alcance dessas políticas necessitam de efetivas ações e interações entre as demandas e necessidades dos setores produtivos e da sociedade e as capacitações já existentes nas instituições científicas e tecnológicas, sendo que essas políticas em relação de ciência, tecnologia e inovação serão de responsabilidade das autoridades nacionais e provinciais. A Secretaria para la Tecnologia, la Ciência y la Innovación Productiva (SETCyT) atua na programação, articulação e coordenação em todos os níveis através do monitoramento e avaliação. A Agencia Nacional de Promoción Científica y Tecnológica (ANPCyT) promove a pesquisa e a inovação no setor público e privado por meio de subsídios e mecanismos fiscais e financeiros, tais como o FONTAR e o FONCYT. O Consejo Nacional de Investigaciones Científicas y Técnicas (CONICET) executa projetos de pesquisa mas também atua na promoção e fomento. Há também o Programa de Consejerías que visa apoiar a pequena e média indústria (PyME) através da vinculação a instituições tecnológicas e universidades com o objetivo de identificar suas necessidades e demandas.

Com propósito de fomentar as vinculações que são o principal enfoque de um SNI, terão prioridade os projetos que fomentem redes de pesquisa, onde haja a participação de pesquisadores de uma mesma universidade, de diferentes universidades ou até mesmo com instituições e universidades de outros países criando-se assim convênios de cooperação internacional.
Com relação ao setor privado, com o objetivo de uma maior participação das pequenas e médias empresas nos projetos de $\mathrm{P} \& \mathrm{D}$ a disponibilização de novas linhas de crédito e outros instrumentos de financiamento irão fomentar maiores esforços nas atividades tecnológicas por parte dessas empresas. As principais demandas são o acesso a informações sobre tecnologias de processos e produtos, melhorias na qualidade dos produtos e normas técnicas. A assessoria técnica na otimização do processo produtivo, produtos de maior complexidade tecnológica, adequação das matérias-primas, controle de qualidade, reestruturação da empresa e busca de novos nichos de mercado são algumas de suas necessidades específicas para melhorar suas competências e capacitações. As instituições públicas, universidades e outras empresas deverão procurar serem mais flexíveis na oferta de serviços, pois só assim diagnosticarão com maior facilidade os problemas tecnológicos e encontrarão as possíveis soluções.

As grandes empresas nacionais e as sucursais das empresas transnacionais, na sua maioria realizam P\&D com seus próprios recursos humanos e algumas vezes em convênios com instituições de pesquisa locais, além de investir em bens de capital importados e também recorrerem a licenciamentos e assistência técnica no exterior com a finalidade de absorvê-las, adaptá-las e gerar inovações de produtos e processos. Entretanto, a informação disponível para a análise deste complexo processo de destruição criativa é altamente fragmentada e somente por ser estudada em algumas empresas transnacionais e grandes empresas nacionais. O segmento de termoplásticos é constituído principalmente pelas resinas que são consideradas commodities: Polietileno de alta densidade (PEAD), Polietileno de baixa densidade (PEBD), Polietileno de baixa densidade linear (PEBDL) e o Polipropileno (PP) que são conhecidos como poliolefinas; o Policloreto de vinila (PVC), e o Poliestireno (PS).

A hierarquização do grau de dinamismo do investimento setorial resulta da comparação entre as estimativas das taxas de acumulação correntes (participação do investimento no PIB) no triênio 1995/1997 com o registro histórico do IBGE entre 1970/1988 (média do período). Alguns setores industriais, considerados mais dinâmicos; elevaram sua participação no total dos investimentos na economia brasileira, investindo cerca de 1,9\% do PIB no triênio 1995/1997. 
O segmento de termoplásticos, está entre esses setores tendo investido cerca de $0,12 \%$ do $\mathrm{PIB}^{[15]}$.

Numa primeira aproximação, pode-se concluir que o setor de termoplásticos, além do setor siderúrgico - tradicionalmente um setor de alta competitividade da indústria brasileira - foi beneficiado com a elevação da capacidade de consumo (via aumento de salários e forte ampliação do crédito direto ao consumidor promovidos pelo Plano Real) que, por diferentes motivos, não estiveram pressionados por forte concorrência das importações $^{[15]}$.

As externalidades tecnológicas geradas pela presença das filiais das empresas transnacionais podem ser fracas devido a pouca envergadura das atividades inovadoras e as poucas vinculações com fornecedores, universidades e centros de pesquisa locais. Mas é possível, devido ao atual processo de globalização da economia mundial, que as empresas transnacionais e as empresas nacionais aumentem lenta e espontaneamente seus esforços tecnológicos, bem como suas atividades inovadoras e invistam pouco a pouco em atividades que utilizem o uso de conhecimentos, sejam mais eficientes, melhorem a produtividade e qualidade. Sem dúvida, este é um processo bem heterogêneo pois diz respeito ao tipo de atividades, tamanho das firmas e localização geográfica.

$\mathrm{O}$ aumento dos recursos financeiros, a mudança na gestão das instituições e a modificação da maneira como distribuir fundos para as pesquisas são formas de introduzir mecanismos que induzam a competitividade. As instituições devem identificar e formular planos estratégicos das prioridades institucionais, as metas e resultados a serem alcançados e os mecanismos de auto-avaliação em função do novo contexto que operam a economia e a sociedade. Com relação à gestão, esta deverá ser mais flexível e contemplar a possibilidade da incorporação de incentivos para os recursos humanos engajados no cumprimento das metas e resultados ao mesmo tempo que participem de atividades relacionadas com a tecnologia.

\section{Proposta de um SNI para os termoplásticos}

Ao longo dos últimos anos, o segmento industrial produtor de resinas termoplásticas, em ambos os países, não só sofreu modernizações mas também introduziu novos grades de produtos no mercado pela expansão significativa da capacidade instalada bem como sofreu um processo de reestruturação resultan- do em ganhos expressivos de eficiência e produtividade. Este processo envolveu não só mudanças no âmbito empresarial, mas também em toda cadeia produtiva. É inquestionável que os ganhos de competitividade obtidos nos últimos anos dependem ainda da estabilidade econômica no Mercosul; da redução do custo dos fatores que compõem a infra-estrutura operacional e logística e sobretudo do surgimento de parcerias e intercâmbios entre as empresas produtoras de termoplásticos, os centros de pesquisa tanto públicos como privados e de serviços técnicos, as universidades e outras instituições educativas com o objetivo de absorver, gerar e difundir o conhecimento e as inovações tecnológicas, através da capacitação dos recursos humanos o que resultaria na alteração de seu padrão de inserção internacional.

A incorporação de novos equipamentos e a introdução de técnicas mais modernas de gestão permitiram que esse setor industrial melhorasse sua competitividade. Entretanto, este segmento ainda enfrenta dificuldades de investir em P\&D devido às necessidades de inovações organizacionais bem como o esforço em atividades de inovação in house tem sido complementado pela aquisição de tecnologias intangíveis ( licenciamentos, assistência técnica, aquisição de softwares e consultorias). Uma outra dificuldade refere-se ao fato que seus produtos devem ser diferenciados para poderem ser competitivos no mercado externo, pois assim estarão buscando nichos de mercado entretanto as inovações significativas são muitas vezes provenientes do desenvolvimento de outras tecnologias nem sempre acessíveis às empresas. A incessante busca e conquista dos nichos de mercado são asseguradas pela obtenção de patentes referentes aos seus desenvolvimentos tecnológicos, sendo este o padrão de comportamento usual das empresas atuantes nesse setor industrial.

As parcerias entre universidades e centros de pesquisa no país são interessantes às empresas entretanto, às vezes é necessário para as atividades de cooperação tecnológica recorrer às instituições no exterior mas as empresas estão mais propícias a estreitar seus relacionamentos com as instituições do próprio país.

O segmento de termoplásticos deve articularse em quatro planos distintos de retroalimentações constantes com o objetivo do fomento do fluxo 
Ferreira Netto, M. J. S. et al. - Sistema nacional de inovação

Tabela 3. Empresas Produtoras de Termoplásticos e sua Composição Acionária

\begin{tabular}{|c|c|c|c|c|}
\hline \multirow{2}{*}{ Produdos } & \multicolumn{4}{|c|}{ Empresas Produtoras } \\
\hline & Brasil & Composição Acionária & Argentina & Composição Acionária \\
\hline \multirow[t]{5}{*}{ PEAD/PEBDL } & Ipiranga Petroquímica & $\begin{array}{l}\text { capital brasileiro }-93,54 \% \\
\text { capital estrangeiro }-6,46 \%\end{array}$ & \multirow[t]{5}{*}{ Polisur } & \multirow[t]{5}{*}{$\begin{array}{l}\text { capital argentino }-30 \% \\
\text { capital estrangeiro }-70 \%\end{array}$} \\
\hline & OPP Polietilenos & $\begin{array}{l}\text { capital brasileiro }-98,78 \% \\
\text { capital estrangeiro }-1,22 \%\end{array}$ & & \\
\hline & Polialden & $\begin{array}{l}\text { capital brasileiro }-66,66 \% \\
\text { capital estrangeiro }-33,34 \%\end{array}$ & & \\
\hline & Politeno & $\begin{array}{l}\text { capital brasileiro }-70 \% \\
\text { capital estrangeiro }-30 \%\end{array}$ & & \\
\hline & Solvay Polietileno & $100 \%$ capital estrangeiro & & \\
\hline \multirow[t]{4}{*}{ PEBD } & OPP Polietilenos & $\begin{array}{l}\text { capital brasileiro - } 98,78 \% \\
\text { capital estrangeiro - 1,22\% }\end{array}$ & \multirow[t]{4}{*}{ Polisur } & \multirow[t]{4}{*}{$\begin{array}{l}\text { capital argentino }-30 \% \\
\text { capital estrangeiro }-70 \%\end{array}$} \\
\hline & Politeno & $\begin{array}{l}\text { capital brasileiro }-70 \% \\
\text { capital estrangeiro }-30 \%\end{array}$ & & \\
\hline & Petroquímica Triunfo & $100 \%$ capital brasileiro & & \\
\hline & Union Carbide & $100 \%$ capital estrangeiro & & \\
\hline \multirow[t]{3}{*}{$\mathrm{PP}$} & Ipiranga Petroquímica & $\begin{array}{l}\text { capital brasileiro }-93,54 \% \\
\text { capital estrangeiro }-6,46 \%\end{array}$ & Petroken & $\begin{array}{l}\text { capital argentino }-50 \% \\
\text { capital estrangeiro }-50 \%\end{array}$ \\
\hline & OPP Petroquímica & $100 \%$ capital brasileiro & \multirow[t]{2}{*}{ Petroquímica Cuyo } & \multirow[t]{2}{*}{$100 \%$ capital argentino } \\
\hline & Polibrasil Resinas & $\begin{array}{l}\text { capital brasileiro - 50\% } \\
\text { capital estrangeiro - 50\% }\end{array}$ & & \\
\hline \multirow[t]{2}{*}{ PVC } & Trikem & $\begin{array}{l}\text { capital brasileiro }-66,53 \% \\
\text { capital estrangeiro }-23,47 \%\end{array}$ & \multirow[t]{2}{*}{ Solvay-Indupa } & \multirow[t]{2}{*}{$100 \%$ capital estrangeiro } \\
\hline & Solvay-Indupa & $100 \%$ capital estrangeiro & & \\
\hline \multirow[t]{2}{*}{ PS } & Basf Poliestireno & $100 \%$ capital estrangeiro & \multirow[t]{2}{*}{ Pecon Energia } & \multirow[t]{2}{*}{$100 \%$ capital argentino } \\
\hline & EDN/EDN Sul & $100 \%$ capital estrangeiro & & \\
\hline
\end{tabular}

Fontes: Anuário da ABIQUIM ${ }^{[16]} /$ Anuário IPA ${ }^{[17]}$

de inovações tecnológicas, da capacitação de recursos humanos, do aprimoramento da gestão empresarial e ambiental, do aumento da competitividade:

\section{Rede científico-tecnológica-acadêmica}

universidades, centros de pesquisa, entre outros

\section{Rede empresarial}

organismos de classe e empresas produtoras

\section{Rede institucional}

instituições de fomento, organismos relacionados com a C\&T tanto no âmbito local como nacional. Rede internacional

universidades, centros de pesquisa, organismos relacionados com a $\mathrm{C} \& \mathrm{~T}$ do exterior

O objetivo da rede científico-tecnológica-aca- 
dêmica é incrementar as relações existentes entre essas instituições através do fomento de pesquisas conjuntas, intercâmbios, consultorias, capacitação de recursos humanos bem como a utilização de equipamentos e laboratórios para testes e ensaios, com relação às universidades e centros de pesquisa no Brasil há o CENPES, IMA, UFSCar, UFRGS, entre outros e com respeito à Argentina o PLAPIQUI, INTEC, INTEMA, entre outros. Já o objetivo da rede empresarial é a modernização do setor produtivo mediante os mais diversos mecanismos de geração, absorção, transferência e difusão da tecnologia bem como atender as necessidades e demandas do setor transformador de resinas termoplásticas na grande maioria composto de pequenas e médias empresas, elo final dessa cadeia produtiva; nesta categoria incluímos a Associação Brasileira da Indústria Química e de Produtos Derivados (ABIQUIM), o Instituto Brasileiro do Petróleo (IBP), o Instituto Petroquímico Argentino (IPA), a Cámara de la Industria Química y Petroquímica de Argentina (CIQyP), o SEBRAE, o Programa de Consejerías. Por outro lado, a rede institucional que inclui o CNPq, a FINEP, entre outras instituições no Brasil e o CONICET, a SETCyT na Argentina; deve propiciar o desenvolvimento de uma cultura territorial através das melhorias da qualidade de vida, da utilização mais racional das infra-estruturas físicas e humanas disponíveis (transportes, comunicações, tecnologias da informação, energia, entre outras). Por último a rede internacional composta pelas fontes de informações tecnológicas, contatos e importantes oportunidades para o setor produtivo na qual se insere devendo manter acordos de cooperação tanto acadêmicos como empresariais no exterior principalmente no âmbito do Mercosul, como já ocorre entre o Brasil (IMA/UFRJ) e a Argentina (INTEMA/ UNMdP) através do desenvolvimento de pesquisas acadêmicas em polímeros termoplásticos bem como o convênio existente entre o PLAPIQUI/UNS/Argentina e a UFRGS/Brasil.

Com relação ao Brasil e Argentina há ainda alguns aspectos que podem dificultar a viabilização dos objetivos e das políticas setoriais. A dificuldade da obtenção de financiamentos e linhas de crédito a longo prazo, o incipiente intercâmbio entre o sistema educativo, produtivo e as instituições científicas, os padrões de comportamento do setor privado.

\section{Conclusões}

As políticas de ciência e tecnologia já sinalizam que estão ocorrendo modificações institucionais e que a questão científica-tecnológica está sendo revigorada. Os pontos fundamentais para a superação da fragilidade tecnológica e da ausência de cooperação são: esboço de uma estratégia a nível nacional tanto para o Brasil como para a Argentina de desenvolvimento científico e tecnológico articulada às estratégias de desenvolvimento empresarial das empresas; estímulo ao setor empresarial objetivando reformular suas atividades de $\mathrm{P} \& \mathrm{D}$ através de programas que demonstrem o potencial de novas tecnologias e das inovações nos próximos anos; aumento dos vínculos entre os agentes componentes do sistema de C\&T de cada país e o fomento para cooperação e aprendizagem conjuntas entre o Brasil e a Argentina; promoção da rearticulação da infra-estrutura tecnológica no âmbito governamental e empresarial.

Com relação ao Brasil, a criação dos fundos setoriais de apoio ao desenvolvimento tecnológico, coordenados pelo MCT, instituem um modelo inovador de gestão de programas de desenvolvimento científico e tecnológico, pois contarão com a participação de representantes do governo, da comunidade científica e das empresas em seus comitês. A partir da modernização tecnológica, produtos de melhor qualidade ocasionarão uma maior rentabilidade para as empresas e estas serão mais competitivas no mercado externo.

Já em relação a Argentina o Plan Nacional Plurianual de Ciencia y Tecnologia objetiva a melhoria, aumento e eficiência do esforço público e privado em C\&T bem como o aumento dos investimentos governamentais em atividades de maior impacto social e econômico, o desenvolvimento de atividades econômicas, sociais e culturais utilizando os recursos humanos capacitados em C\&T.

A criação de uma política setorial que implique na promoção de ações que além de incluir a defesa da concorrência, devam fomentar os vínculos inter-empresas e entre empresas, associações de classe, universidades e centros de pesquisa em nível regional e nacional, a promoção da pesquisa básica pelas empresas, a disponibilidade de serviços de assessoria e consultoria; o trabalho das incubadoras de empresas e os programas de capacitação de recursos humanos. A intervenção governamental, em ambos os países, 
deve desempenhar um papel catalisador em C\&T, potenciando a tecnologia e as inovações em todo o setor produtor de termoplásticos, concentrando esforços que assegurem uma infra-estrutura adequada e gere incentivos que estimulem as interações entre os vários agentes e instituições que possam desenvolver e participar de um SNI para o segmento de termoplásticos.

\section{Agradecimentos}

A Fundação Coordenação de Aperfeiçoamento de Pessoal de Nível Superior (CAPES)

\section{Referências bibliográficas}

1. Ocampo, J.A. - Revista de la CEPAL, 66, p.67 (1998).

2. OCDE - "Technology And The Economy. The Key Relationships", Paris (1992).

3. OCDE - "OCDE Programme On National Innovation Systems", Paris (1996).

4. Mytelka, L. - 'Strategic Partnering: Some Lessons For Latin America”, Université de Paris, Paris (1992).

5. Freeman, C. - “Japan: A New National System Of Innovation?" in: Technical Change And Economic Theory, Pinter Publishers, Londres (1988).

6. Lundvall, B. - "National Systems Of Innovation. Towards A Theory Of Innovation And Interactive Learning”, Pinter Publishers, Londres (1992).

7. Nelson, R. - "National Innovation Systems. A Comparative Analysis", Oxford University Press, Nova York (1993).
8. Edquist, C. - "Systems Of Innovation: Technologies, Institutions And Organizations", Pinter Publishers, Londres (1997).

9. Mytelka, L. - "Competition, Innovation And Competitiveness: A Framework For Analysis" in: Competition, Innovation And Competitiveness In Developing Countries, OECD Development Centre, Paris (1996).

10. Teece, D. J. - Research Policy, 15, p.285 (1986).

11. Cassiolato, J.E. e Lastres, H. - "Inovação e competitividade na indústria brasileira no anos 90", UNICAMP, Campinas (1997).

12. Lall, S. - Science And Public Policy, 23, p.109 (1996)

13. Chudnovsky, D. - Revista de la CEPAL, 67, p.153 (1999).

14. Brito Cruz, C.H. - "O setor de $C \& T$ como parte do sistema de inovação brasileiro", Conselho Nacional de Ciência e Tecnologia, Brasília (2000).

15. Bielschowsky, R.; Abicalil, M. T.; Oliveira, J. C.; Soares, S. e Wholers, M. - "Formação de capital no ambiente das reformas econômicas brasileiras nos anos 1990: Uma abordagem setorial" in: Brasil, uma Década de Transição, Editora Campus Ltda, Rio de Janeiro (2000).

16. ABIQUIM - "Anuário da Associação Brasileira da Indústria Química e de Produtos Derivados", São Paulo (1999/2000).

17. IPA - "Información Estadística de la Industria Petroquímica y Química de la Argentina", 19a Edición, Buenos Aires (1999)

Recebido: 06/10/00

Aprovado: 08/02/01 